\title{
Caesarean delivery rates, determinants and indications in Makassed Hospital, Jerusalem 1993 and 2002
}

\author{
N. Mikki, ${ }^{1}$ N.M.E. Abu-Rmeileh, ${ }^{1}$ L. Wick, ${ }^{1}$ N. Abu-Asab ${ }^{2}$ and S. Hassan-Bitar ${ }^{1}$
}

$$
\begin{aligned}
& \text { معدَّل الولادات القيصرية ومحدِّداتها ودواعي إجر ائها في مستشفى المقاصد، في القدس بين عامَيْ } 1993 \text { و و2002 }
\end{aligned}
$$

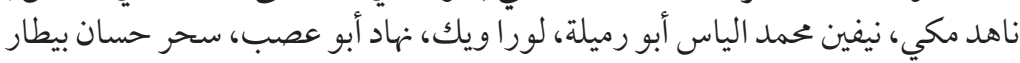

$$
\begin{aligned}
& \text { الخلاصـة: قام الباحثون باستقصاء الارتفاع المتزايد في معدَّلات الولادات القيصرية عما كان عليه عام } 1993
\end{aligned}
$$

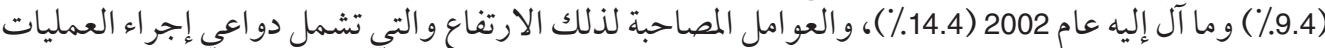

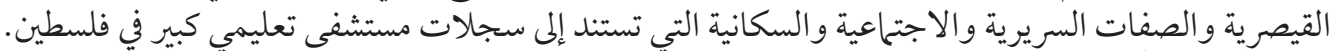

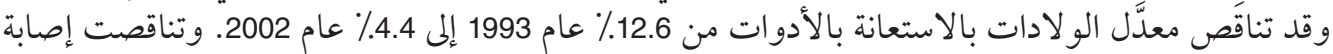

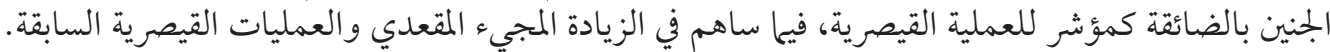

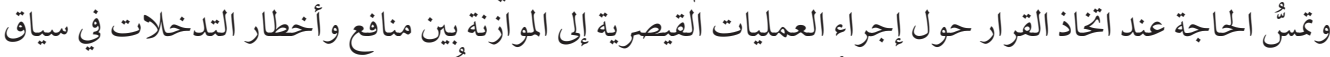

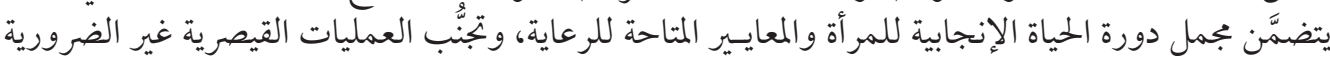

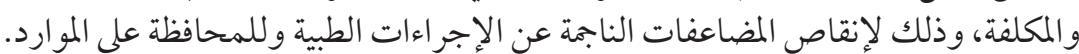

ABSTRACT This study investigated the rising rate of caesarean section (CS) deliveries between 1993 and 2002 (9.4\% to 14.4\%) and associated factors, including indications for CS and sociodemographic and clinical characteristics based on the register of a major Palestinian teaching hospital. Instrumental deliveries declined from $12.6 \%$ to $4.4 \%$. Fetal distress decreased as an indication for CS, while previous CS and breech presentations contributed to the increase. Decision-making for CS needs to frame the benefits and risks of the intervention within the context of women's entire reproductive life-cycle and existing standards of care, avoiding unnecessary and costly CS deliveries to reduce iatrogenic complications and conserve resources.

Taux, déterminants et indications en matière d'accouchements par césarienne à l'hôpital Makassed de Jérusalem entre 1993 et 2002

RÉSUMÉ Cette étude a examiné l'accroissement du taux d'accouchements par césarienne entre 1993 et 2002 (de 9,4 à 14,4 \%) et les facteurs associés, notamment les indications de césarienne et les caractéristiques sociodémographiques et cliniques, d'après le registre du plus grand hôpital universitaire palestinien. Les accouchements instrumentaux ont chuté de 12,6\% à 4,4\%. La part de la détresse fœtale dans les indications de césarienne a baissé, alors que les antécédents de césarienne et la présentation par le siège ont contribué à l'augmentation du nombre de ces accouchements. Avant de prendre une décision en matière de césarienne, il convient de définir les avantages et les risques de l'intervention sous l'angle de l'ensemble de la période de procréation de la femme et du niveau de soins existant, en évitant des césariennes inutiles et coûteuses afin de réduire les complications iatrogènes et de préserver les ressources.

IInstitute of Community and Public Health, Birzeit University, Ramallah, West Bank, Occupied Palestinian Territory (Correspondence to N.M.Abu-Rmeileh: nrmeileh@birzeit.edu).

${ }^{2}$ Makassed Hospital, East Jerusalem, Occupied Palestinian Territory.

Received: 05/10/06; accepted: 11/01/07 


\section{Introduction}

The appropriate use of caesarean delivery has been a public health concern for decades. However, determining what is appropriate in a specific context is a complex question. While research in many settings is focusing on the controversy of maternal request for a caesarean section (CS) operation [1], the rising trend in CS births in some developing countries raises questions about the implications for weak and under-resourced health systems and the consequences for maternal and neonatal health. This study aimed to investigate the reasons for the rising CS operation rate over the past decade in the leading Palestinian teaching and referral hospital by conducting a comparative record audit of 2 years of the hospital maternity register.

The risk of maternal death with CS delivery is 3-7 times greater than for vaginal delivery [2]. A higher risk of serious neonatal respiratory problems has also been associated with CS [3]. The national, population-based CS delivery rate in the Palestinian Territory has almost doubled in 8 years, increasing from $6.8 \%$ in 1996 to $12.4 \%$ in 2004 [4]. While this rate is still considerably lower than in some Latin American countries [5], the rapid increase is alarming, particularly in the light of the high total fertility rate of $4.6[4]$ and the associated risk of complications in the postpartum period and in subsequent pregnancies after a CS delivery $[6,7]$. With the aim of preventing unnecessary operations in suboptimal conditions which could increase short- and long-term maternal and neonatal mortality and morbidity and health care costs [8], it is timely to investigate the causes for this rise, as it is difficult to reduce the rate once it has increased [9].

As no published research exists on CS operations in Palestine aside from the national population rate mentioned previously, we investigated the rising trend and indications for CS operations of singleton deliveries in Makassed Hospital in Jerusalem. Auditing the change in clinical indications in 1993 and in 2002 was a first step in identifying policies and practices which contributed to the obstetricians' decisions favouring CS operation over vaginal birth.

\section{Methods}

Data on singleton deliveries in 1993 and 2002 were collected from the birth register of Makassed Hospital. This charitable hospital was chosen as it is the major teaching and referral hospital and thus influences obstetric practice throughout the country. Unlike some private maternity facilities, the obstetricians and midwives at Makassed use the same standardized guidelines and models of care. Midwives are responsible for most normal births, and high-risk cases are conducted by the doctors.

The rates of CS and instrumental deliveries and selected CS determinants and indications were studied for each year. Variables included: the baseline characteristics of the study group (locale, region, age, antenatal booking visits); current obstetric conditions (parity, previous CS, antepartum haemorrhage, pregnancy-induced hypertension, weeks of gestation, weight and presentation of the baby); and current medical conditions (diabetes, haematological disorders, etc.). Indications for CS deliveries included fetal distress, previous CS, antepartum haemorrhage, pre-eclampsia/eclampsia, dystocia and breech presentation. All the indications that were written in the register were included in the study. In certain cases there was more than 1 indication for a CS, but the indications were not listed in any order of importance.

المجلة الصحية لشرق المتوسط، منظمة الصحة العالمية، المجلد الخنامس عشر، العدد ع، 9 +. 


\section{Statistical analysis}

The data in the register were coded by midwives and analysed using SPSS, version 12, software. The chi-squared test was used to compare frequencies. Statistical significance was set at $P$-value $<0.05$. Multiple logistic regression was used first to study changes in the CS rate among groups with different characteristics in both years, and then to study the association between the mode of delivery and certain sociodemographic characteristics and current obstetric and medical conditions. Indications for CS delivery were compared using the difference between proportions.

\section{Results}

In 1993 the hospital CS rate was $9.7 \%$ of all deliveries and $9.4 \%$ of singleton deliveries, which increased in 2002 to $15.3 \%$ of all deliveries and $14.4 \%$ of singleton deliveries. As mentioned above, this study included only the singleton deliveries, which totalled 6804 (3356 in 1993 and 3448 in 2002).

While around two-thirds of the women came from urban areas in both years, fewer came from the West Bank in 2002 (5.8\%) compared with 1993 (38.0\%). The ratio of primiparas to multiparas remained the same (1:3). More women came to the hospital without antenatal booking in 2002 (54.9\%) than in $1993(40.0 \%)$ (Table 1).

More women were admitted with $\geq 1$ previous CS in 2002 (12.9\%) than in 1993 $(8.6 \%)$ (Table 1). Recorded obstetric and medical conditions also differed between the 2 years. In 1993 there were almost twice as many cases of pregnancy-induced hypertension and antepartum haemorrhage than in 2002, whereas the number of pregnant women diagnosed with diabetes increased in 2002. Preterm and post-term deliveries were fewer in 2002 than in 1993.
The mode of delivery changed significantly between the 2 years (Figure 1). The instrumental delivery rate decreased from $12.6 \%$ (423 deliveries) to $4.4 \%$ (153 deliveries) with vacuum delivery declining from $4.7 \%$ (159 deliveries) to $2.3 \%$ (80 deliveries) and forceps delivery from $7.4 \%$ (249 deliveries) to $2.0 \%$ (70 deliveries). The overall CS rate increased considerably from 9.4\% (316 deliveries) in 1993 to $14.4 \%$ (497 deliveries) in 2002, including a rise in the emergency $\mathrm{CS}$ rate from $7.7 \%$ (257 deliveries) to $10.2 \%$ (350 deliveries) and the elective CS rate from $1.8 \%$ (59 deliveries) to $4.3 \%$ (147 deliveries). This increase in the CS rate was not accompanied by a decrease in the normal vaginal delivery rate; from 78.0\% (2617 deliveries) in 1993 to $81.1 \%$ (2798 deliveries) in 2002. The rate of vaginal birth after CS (VBAC) was $57.4 \%$ in 1993 (166 out of 289 women with previous CS) while in 2002 it was reduced to $53.2 \%$ (238 out of 447 women with previous CS).

Among CS cases, there was an increase in the CS rate in groups with different characteristics in 2002 compared to 1993: more specifically in age groups 20-35 years and $>35$ years, in women coming from Jerusalem, the West Bank and the Gaza Strip, in both primiparous and multiparous women, in women with a first CS, in cases of hypertension and pre-eclampsia, in other conditions related to pregnancy, in full-term, preterm and post-term babies and in cases of low birth weight, high birth weight and normal birth weight (Table 2). However, when the CS rate was compared in these groups in a logistic regression model, the only characteristic which remained significant was region (being from the West Bank and Gaza Strip).

The results of multiple logistic regressions of selected determinants associated 
Table 1 Baseline characteristics of women who gave birth at Makassed Hospital in the two study years

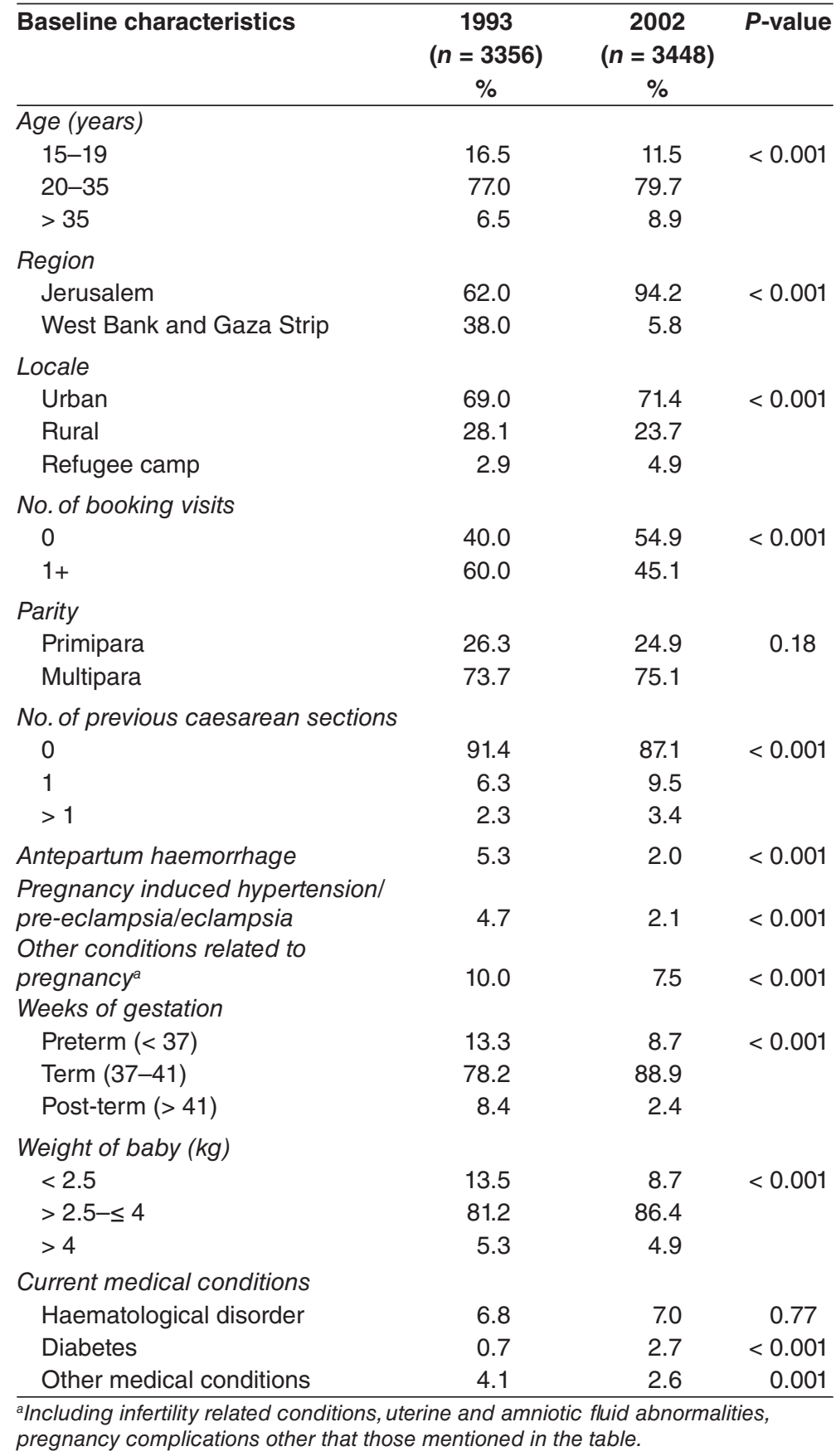

المجلة الصحية لشرق المتوسط، منظمة الصحة العالمية، المجلد الخامس عشر، العدد ع، 9 +. 
with CS are presented in Table 3. This model shows that irrespective of the year, region (being from the West Bank), having a previous CS, having other conditions related to pregnancy, having antepartum haemorrhage, having pregnancy-induced hypertension, younger age group (15-19 years) and older age group (>35 years), small and large babies, preterm babies and primiparity were all associated with CS.

The indications for CS changed over the 2 years (Table 4 ). The main indications in 1993 were fetal distress $(38.3 \%)$ and previous CS (38.9\%), while in 2002 they were previous CS (42.1\%) and breech presentation (24.7\%). Fetal distress, antepartum haemorrhage and dystocia decreased significantly as indications for CS in 2002, while breech presentation increased significantly in the same year. The indications of previous CS and breech presentation out of all deliveries also increased significantly in 2002. As indications for CS, previous CS almost doubled in 2002 compared to 1993 (from $3.7 \%$ to $6.1 \%$ ) and breech presentation almost tripled (from $1.1 \%$ to $3.6 \%$ ).

Some of the indications for CS changed markedly between the 2 study years. Fetal distress went down from $38.3 \%$ of CS deliveries in 1993 to $13.9 \%$ in 2002 ( $P$ $<0.001$ ) (Table 4). Dystocia $(P<0.001)$ and antepartum haemhorrage $(P=0.03)$ also went down significantly while breech presentation increased from $11.4 \%$ of CS deliveries in 1993 to $24.7 \%$ in $2002(P$ $<0.001$ ).

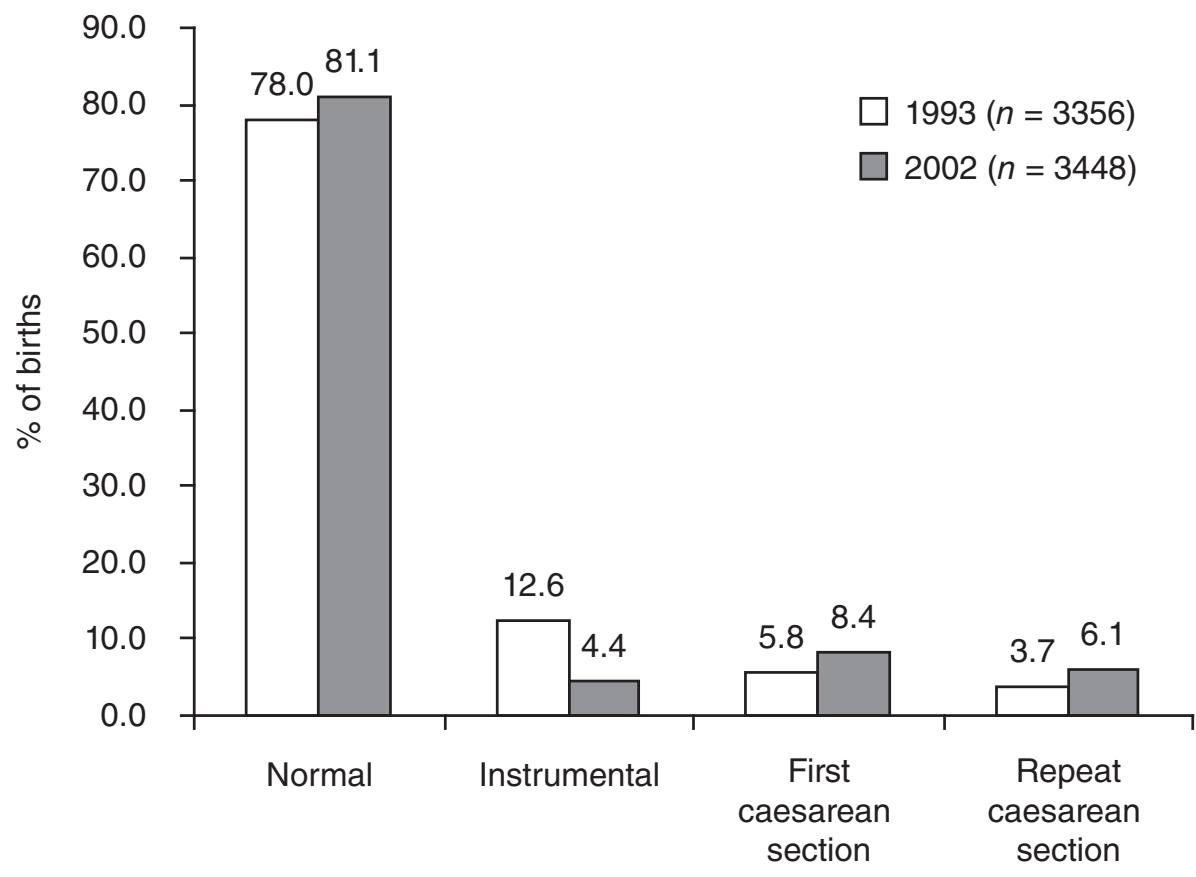

Mode of delivery

Figure 1 Distribution of mode of delivery in the two study years for births at Makassed Hospital

المجلة الصحية لشرق المتوسط، منظمة الصحة العالمية، المجلد الخامس عشر، العدد ع، 9 +. 
Table 2 Changes in caesarean section (CS) rate comparing the two study years according to selected demographic, obstetric and medical characteristics

\begin{tabular}{|c|c|c|c|c|}
\hline \multirow[t]{2}{*}{ Selected characteristics } & \multicolumn{2}{|c|}{ CS rate } & \multirow{2}{*}{$\begin{array}{c}\text { Unadjusted } \\
P \text {-value }\end{array}$} & \multirow{2}{*}{$\begin{array}{l}\text { Adjusted } \\
P \text {-value }\end{array}$} \\
\hline & $\begin{array}{c}1993(n=3356) \\
\%\end{array}$ & $\begin{array}{c}2002(n=3448) \\
\%\end{array}$ & & \\
\hline \multicolumn{5}{|l|}{$\overline{\text { Age (years) }}$} \\
\hline $15-19$ & 4.7 & 7.9 & 0.04 & 0.07 \\
\hline 20-35 & 9.6 & 13.7 & $<0.001$ & \\
\hline$>35$ & 18.8 & 30.7 & 0.002 & \\
\hline \multicolumn{5}{|l|}{ Region } \\
\hline Jerusalem & 5.9 & 13.5 & $<0.001$ & $<0.001$ \\
\hline West Bank and Gaza Strip & 14.9 & 30.7 & $<0.001$ & \\
\hline \multicolumn{5}{|l|}{ Parity } \\
\hline Primipara & 9.4 & 13.1 & 0.009 & 0.12 \\
\hline Multipara & 9.4 & 14.9 & $<0.001$ & \\
\hline \multicolumn{5}{|l|}{$\begin{array}{l}\text { No. of previous caesarean } \\
\text { sections }\end{array}$} \\
\hline 0 & 6.3 & 9.6 & $<0.001$ & 0.69 \\
\hline $1+$ & 42.6 & 47.0 & 0.14 & \\
\hline \multicolumn{5}{|l|}{ Antepartum haemorrhage } \\
\hline No & 8.8 & 13.4 & $<0.001$ & 0.27 \\
\hline Yes & 20.1 & 60.0 & $<0.001$ & \\
\hline \multicolumn{5}{|c|}{$\begin{array}{l}\text { Pregnancy-induced hypertension/ } \\
\text { pre-eclampsia/eclampsia }\end{array}$} \\
\hline No & 8.6 & 13.8 & $<0.001$ & \\
\hline Yes & 26.6 & 41.9 & $<0.001$ & 0.19 \\
\hline \multicolumn{5}{|l|}{$\begin{array}{l}\text { Other conditions related to } \\
\text { pregnancyc }\end{array}$} \\
\hline No & 8.6 & 12.7 & $<0.001$ & 0.30 \\
\hline Yes & 16.7 & 36.0 & $<0.001$ & \\
\hline \multicolumn{5}{|l|}{ Weeks of gestation } \\
\hline Preterm $(<37)$ & 17.5 & 33.4 & $<0.001$ & 0.74 \\
\hline Term (37-41) & 8.3 & 12.5 & $<0.001$ & \\
\hline Post-term (> 41) & 7.9 & 17.3 & 0.01 & \\
\hline \multicolumn{5}{|l|}{ Weight of baby (kg) } \\
\hline$\leq 2.5$ & 16.9 & 30.5 & $<0.001$ & 0.94 \\
\hline$>2.5-\leq 4$ & 8.1 & 12.1 & $<0.001$ & \\
\hline$>4$ & 11.2 & 24.9 & 0.001 & \\
\hline \multicolumn{5}{|l|}{ Other medical conditions ${ }^{d}$} \\
\hline No & 9.0 & 14.0 & $<0.001$ & 0.17 \\
\hline Yes & 18.7 & 28.6 & 0.08 & \\
\hline
\end{tabular}

${ }^{a}$ Bivariate analyses, P-value for change in CS rate between the 2 years and individual variable.

${ }^{b}$ Logistic regression for CS cases testing the change of selected variables (identified as significant in the bivariate analysis) between the 2 years.

Including infertility related conditions, uterine and amniotic fluid abnormalities, pregnancy complications other than those mentioned in the table.

IIncluding medical conditions other than diabetes and haematological disorders.

المجلة الصحية لشرق المتوسط، منظمة الصحة العالمية، المجلد الخامس عشر، العدد ع، 9 . ب 


\begin{tabular}{|c|c|c|c|}
\hline Selected characteristics & OR & $95 \% \mathrm{Cl}$ & $P$-value \\
\hline \multicolumn{4}{|l|}{ Year of birth } \\
\hline 1993 & 1 & & \\
\hline 2002 & 2.00 & $1.66-2.40$ & $<0.001$ \\
\hline \multicolumn{4}{|l|}{ Age (years) } \\
\hline $15-19$ & 0.44 & $0.32-0.61$ & $<0.001$ \\
\hline 20-35 & 1 & & \\
\hline$>35$ & 2.40 & $1.85-3.11$ & $<0.001$ \\
\hline \multicolumn{4}{|l|}{ Region } \\
\hline Jerusalem & 1 & & \\
\hline West Bank and Gaza Strip & 1.39 & $1.16-1.66$ & $<0.001$ \\
\hline \multicolumn{4}{|l|}{ Parity } \\
\hline Primipara & 1 & & \\
\hline Multipara & 0.42 & $0.34-0.52$ & $<0.001$ \\
\hline \multicolumn{4}{|l|}{$\begin{array}{l}\text { No. of previous caesarean } \\
\text { sections }\end{array}$} \\
\hline 0 & 1 & & \\
\hline $1+$ & 11.78 & $9.60-14.46$ & $<0.001$ \\
\hline \multicolumn{4}{|l|}{ Antepartum haemorrhage } \\
\hline No & 1 & & \\
\hline Yes & 2.87 & $2.04-4.05$ & $<0.001$ \\
\hline \multicolumn{4}{|c|}{$\begin{array}{l}\text { Pregnancy-induced hypertension/ } \\
\text { pre-eclampsia/ eclampsia }\end{array}$} \\
\hline No & 1 & & \\
\hline Yes & 3.25 & $2.29-4.61$ & $<0.001$ \\
\hline \multicolumn{4}{|l|}{$\begin{array}{l}\text { Other conditions related to } \\
\text { pregnancy }^{b}\end{array}$} \\
\hline No & 1 & & \\
\hline Yes & 2.81 & $2.21-3.57$ & $<0.001$ \\
\hline
\end{tabular}

\section{Discussion}

The study focused primarily on a comparison of the medical indications for CS between the 2 years, as some of the nonmedical factors contributing to the rise in CS mentioned in other studies [10] did not seem to apply here. Financial incentives did not play a major role as women from Jerusalem have compulsory health insurance which reimburses the hospital a global fee regardless of the mode of delivery.
Maternal request for CS was also not a significant issue as women's preferences are not usually solicited in clinical decisionmaking about childbirth care. The policies and practices of the obstetricians were thus the main target for investigation of the increase in the $\mathrm{CS}$ rate.

These 2 years were selected as they represented a span of almost a decade where the CS rate rose rapidly. It was also a period when considerable changes occurred 


\begin{tabular}{|c|c|c|c|}
\hline Selected characteristics & OR & $95 \% \mathrm{Cl}$ & $P$-value \\
\hline \multicolumn{4}{|l|}{ Weight of baby (kg) } \\
\hline$<2.5$ & 1.56 & $1.16-2.09$ & 0.004 \\
\hline$>2.5-\leq 4$ & 1 & & \\
\hline$>4$ & 1.86 & $1.33-2.60$ & $<0.001$ \\
\hline \multicolumn{4}{|l|}{ Weeks of gestation } \\
\hline Preterm $(<37)$ & 1.50 & $1.11-2.02$ & 0.008 \\
\hline Term (37-41) & 1 & & \\
\hline Post-term (> 41) & 1.24 & $0.83-1.85$ & 0.28 \\
\hline \multicolumn{4}{|l|}{ Other medical conditions ${ }^{c}$} \\
\hline No & 1 & & \\
\hline Yes & 1.45 & $0.99-2.12$ & 0.06 \\
\hline \multicolumn{4}{|c|}{$\begin{array}{l}\text { a"Diabetes" was excluded from the model because of the small number of cases; } \\
\text { "booking" was excluded because it was not significant in the bivariate analysis; } \\
\text { "Iocality" was excluded because of the high colinearity with "region." } \\
\text { "Including infertility related conditions, uterine and amniotic fluid abnormalities, } \\
\text { pregnancy complications other than those mentioned in the table. } \\
\text { "Including medical conditions other than diabetes and haematological disorders. } \\
\text { OR = odds ratio; } \mathrm{Cl}=\text { confidence interval. }\end{array}$} \\
\hline
\end{tabular}

in the political situation, limiting the access of West Bank Palestinians to Jerusalem, which, in turn, changed the configuration of the hospitals. Most women from the West Bank and some of the staff could not access the hospital in 2002. Makassed could no longer serve as the major referral hospital for the West Bank, which explained the decrease in high-risk cases in 2002. In 1993, most of these high-risk cases were referred from the West Bank to Makassed, whereas in 2002 these women were obliged to give birth in the West Bank. The change in some of the hospital staff may have partially explained the adoption of different clinical policies and practices (such as elective CS for breech presentation) in 2002, reflecting changes in individual obstetricians' practice. The reduction in the proportion of women who received antenatal care at Makassed in 2002 (booking visits) did not reflect a decrease in antenatal coverage but rather a change in the type of health insurance. Women attended antenatal clinics elsewhere and went to Makassed only to give birth without previous booking.

The trends in the mode of delivery for the 2 years indicated that the rise in the CS rate was accompanied by a decrease in the instrumental delivery rate, with a decline in the use of both forceps and vacuum, but a greater reduction for forceps. This decrease in the forceps delivery rate was consistent with the trend in other countries such as England [11]; however, while England maintained the instrumental delivery rate at around $11 \%$ by increasing the use of vacuum, at Makassed the decrease seems to have been compensated for by an increase in the CS rate.

When the determinants of CS were compared to vaginal delivery, irrespective of the year the same determinants were associated with women having a $\mathrm{CS}$, indicating that the rising CS rate could not be attributed to a change in the sociodemographic, obstetric or medical characteristics of the women with CS.

المجلة الصحية لشرق المتوسط، منظمة الصحة العالمية، المجلد الخنامس عشر، العدد ع، 9 +. 
The most significant finding of the study was that the indications for CS changed over the 2-year period. Fetal distress as an indication decreased, probably owing to the change in policy from continuous to intermittent fetal monitoring and better interpretation of fetal heart traces. Antepartum haemorrhage decreased as an indication because the referred cases from the West Bank were treated in West Bank hospitals in 2002. The reduction of dystocia as an indication was most likely due to better management of labour, including more accurate diagnosis of active labour, mobility during labour, eating and drinking as desired, intermittent monitoring of the fetal heart, use of the partogram and support from female relatives [12]. The indications that were likely to have contributed to the rise in the CS rate were primarily breech presentation and repeat $\mathrm{CS}$.

Makassed Hospital adopted a policy of routine elective CS for term breech after the study of the Term Breech Trial [13]. This trial concluded that planned CS delivery is better than planned vaginal delivery for term breech presentation, based on the findings that perinatal and neonatal mortality or serious neonatal morbidity were significantly lower in the planned CS group. The findings were more evident in countries with a low perinatal mortality rate. This randomized controlled trial was very effective in rapidly changing obstetric practice, even in countries such as Palestine which did not have a low perinatal mortality rate. The study has since been shown to have major methodological problems. The inclusion criteria were not always adhered to; there were great inter-institutional differences in the standard of care and in the attendance of clinicians with adequate expertise; and inadequate methods of antepartum and intrapartum fetal assessment methods were used $[14,15]$. Moreover, the subsequent analysis of longer-term outcomes of the infants in the study up to 2 years of age did not show any difference between those born vaginally or by CS [16].

Obstetricians in the Palestinian Territory need to be engaged in the debate regarding the most appropriate management of breech presentation. For the most part, they were quick to adopt a policy of elective CS for breech presentation, without regard for the different context of this country, which has a high fertility rate and suboptimal conditions for CS delivery in many hospitals. The decision to perform CS should be based on strong evidence, given the increased risk of complications associated with this intervention in the postpartum period, in subsequent pregnancies, including ectopic pregnancy and placenta praevia [17], and after multiple repeat CS operations [18]. In addition, routine $\mathrm{CS}$ for breech presentation

\begin{tabular}{|c|c|c|c|c|c|c|c|c|}
\hline \multirow[t]{2}{*}{ Indications } & \multicolumn{2}{|c|}{ No. of cases } & \multicolumn{3}{|c|}{$\%$ of CS deliveries ${ }^{a}$} & \multicolumn{3}{|c|}{$\%$ of total deliveries } \\
\hline & 1993 & 2002 & 1993 & 2002 & $P$-value & 1993 & 2002 & $P$-value \\
\hline Previous CS & 123 & 209 & 38.9 & 42.1 & 0.17 & 3.7 & 6.1 & 0.05 \\
\hline Fetal distress & 121 & 69 & 38.3 & 13.9 & $<0.001$ & 3.6 & 2.0 & 0.09 \\
\hline Dystocia & 45 & 17 & 14.2 & 3.4 & $<0.001$ & 1.3 & 0.5 & 0.12 \\
\hline Breech presentation & 36 & 123 & 11.4 & 24.7 & $<0.001$ & 1.1 & 3.6 & 0.007 \\
\hline Antepartum haemorrhage & 30 & 36 & 9.5 & 7.2 & 0.03 & 0.9 & 1.0 & 0.44 \\
\hline Pre-eclampsia/eclampsia & 13 & 26 & 4.1 & 5.2 & 0.23 & 0.4 & 0.8 & 0.22 \\
\hline
\end{tabular}

aTotal is more than $100 \%$ as there could be more than 1 indication for each CS. 
will lead to a loss of expertise and confidence in delivering breech births vaginally, which will always remain a needed skill for obstetricians in case of emergency. Lack of access to maternity hospitals in this country has led to numerous cases of emergency vaginal breech birth. One doctor in a village clinic north of Jerusalem cut off from the city described how she was obliged to assist women with breech presentation who arrived at her clinic fully dilated. As this had not been part of her obstetric training, she had to refer back to her old textbooks for guidance [19]. Furthermore, a trial of external cephalic version should be carried out whenever possible for all breech presentations, as it has been shown to reduce the CS rate [20]. For the remaining breech presentations, the policy of selective vaginal breech deliveries should be reconsidered, given the overall contextual factors mentioned above.

Repeat CS was the other indication that partially explained the rise in the CS rate at Makassed Hospital. This has been a principal indication contributing to the rise in the CS rate in many countries and VBAC was a major strategy in reducing the rate in the United States of America until the late 1990s [21]. While VBAC has been established as a safe alternative to repeat CS in many cases [22], more recent studies have reopened the debate and certainly contributed to the decline in the number of obstetricians and women who choose the option of trial of labour after a previous CS [23].

Pre-eclampsia/eclampsia was an indication for CS in a small percentage of our cases $(4.1 \%$ in 1993 and $5.2 \%$ in 2002 of CS deliveries), but immediate CS delivery has not been shown to confer any benefit to patients with severe eclampsia [24].

Even though the rise in the CS rate at Makassed was attributed primarily to breech and repeat CS, other strategies should be considered in addition to reducing these 2 indications. Avoiding early admission to the labour ward [25] and unnecessary induction of labour [26], continuing the policy of companionship [27], adopting upright or lateral positions for the second stage of labour [28], and increasing the use of vacuum delivery rather than CS for the management of poor progress in the second stage of labour [17] might be strategies.

\section{Conclusion}

Obstetricians' decision-making for CS is a complex process which needs to frame the benefits and risks of the intervention within the context of the woman's entire reproductive life-cycle and the existing standards of health care. Avoiding unnecessary CS would spare precious resources in the health care system and, most importantly, reduce iatrogenic complications for mothers and neonates.

\section{Acknowledgements}

The authors would like to thank all those Palestinian health providers whose hard work and dedication in assisting these births under difficult conditions form the essential basis for this study, and who nonetheless remain anonymous, their accomplishments being cited in this article as abstract numbers and statistics. The contribution of Emma Gilmore to the data collection was also very much appreciated.

This paper is part of a larger regional research project on Choices and Challenges in Changing Childbirth in the Arab Region, sponsored by the Center for Research on Population and Health at the American University of Beirut, Lebanon, with generous support from the Wellcome Trust. 


\section{References}

1. Wax JR et al. Patient choice cesarean: an evidence-based review. Obstetrical and gynecological survey, 2004, 59(8):601-6.

2. Evaluation of cesarean delivery. Washington, DC, American College of Obstetricians and Gynecologists, 2000.

3. Levine EM et al. Mode of delivery and risk of respiratory diseases in newborns. Obstetrics and gynecology, 2001, 97(3):439-42.

4. Demographics and health survey: final report, 2004. Ramallah, Palestine, Palestinian Central Bureau of Statistics, 2006.

5. Belizan JM et al. Rates and implications of caesarean sections in Latin America: ecological study. British medical journal, 1999, 319:1397-402.

6. Jackson N, Paterson-Brown S. Physical sequelae of caesarean section. Best practice \& research. Clinical obstetrics and gynaecology, 2001, 15(1):49-61.

7. Clement S. Psychological aspects of caesarean section. Best practice and research. Clinical obstetrics and gynaecology, 2001, 15(1):109-26.

8. Mossialos E et al. An investigation of caesarean sections in three Greek hospitals. The impact of financial incentives and convenience. European journal of public health, 2005, 15(3):288-95.

9. Belizan JM et al. Goals in maternal and perinatal care in Latin America and the Caribbean. Birth, 2005, 32(3):210-8.

10. Declercq E et al. Maternal risk profiles and the primary cesarean rate in the United States, 1991-2002. American journal of public health, 2006, 96(5):867-72.

11. Thomas J, Paranjothy S. The national sentinel caesarean section audit report. London, Royal College of Obstetricians and Gynaecologists Press, 2001.
12. Hofmeyr GJ. Evidence-based intrapartum care. Best practice and research. Clinical obstetrics and gynaecology, 2005, 19(1):103-15.

13. Hannah ME et al. Planned caesarean section versus planned vaginal birth for breech presentation at term: a randomised multicentre trial. Lancet, 2000, 356:1375-83.

14. Glezerman M. Five years to the term breech trial: the rise and fall of a randomized controlled trial. American journal of obstetrics and gynecology, 2006, 194:20-5.

15. Keirse M. Evidence-based childbirth only for breech babies. Birth, 2002 , 29(1):55-9.

16. Su M et al. Term breech trial collaborative group: planned caesarean section decreases the risk of adverse perinatal outcome due to both labour and delivery complications in the term breech trial. British journal of obstetrics and gynaecology, 2004, 111:1065-74.

17. Bahl R et al. Outcome of subsequent pregnancy three years after previous operative delivery in the second stage of labour. British medical journal, 2004, 328:311-46.

18. Makoha FW et al. Multiple cesarean section morbidity. International journal of gynaecology and obstetrics, 2004, 87(3):227-32.

19. Wick LC. Making lives under closure: birth and medicine in Palestine's waiting zones [PhD thesis]. Cambridge, Massachusetts, Massachusetts Institute of Technology, 2006:117.

20. Hofmeyr GJ, Kulier R. External cephalic version for breech presentation at term. Cochrane database of systematic reviews, 1996, Issue 2 (CD000083). 
21. Notzon FC et al. Cesarean section delivery in the 1980s: international comparison by indication. American journal of obstetrics and gynecology, 1994, 170(2):495-504.

22. Rageth JC et al. Delivery after previous cesarean: a risk evaluation. Obstetrics and gynecology, 1999, 93:332-7.

23. Walker $\mathrm{R}$ et al. Strategies to address global cesarean section rates: a review of the evidence. Birth, 2002, 29(1):28-39.

24. Coppage KH, Polzin WJ. Severe preeclampsia and delivery outcomes: is immediate cesarean delivery beneficial? American journal of obstetrics and gynecology, 2002, 186:921-3.

25. Rahnama $R$ et al. Impact of early admission in labor on method of delivery.
International journal of gynaecology and obstetrics, 2006, 92:217-20.

26. Heffner LJ et al. Impact of labor induction, gestational age, and maternal age on cesarean delivery rates. Obstetrics and gynecology, 2003, 102(2):287-93.

27. Hodnett ED et al. Continuous support for women during childbirth. Cochrane database of systematic reviews, 2003, 3 (CD003766).

28. Gupta JK, Nikodem VC. Woman's position during the second stage of labor. Cochrane database of systematic reviews, 2000, 2 (CD002006).

\section{Global status report on road safety}

Approximately 1.3 million people die each year on the world's roads, and between 20 and 50 million sustain non-fatal injuries. This report is the first broad assessment of the road safety situation in 178 countries, using data drawn from a standardized survey. According to the results, road traffic injuries remain an important public health problem, particularly for low- and middle-income countries. Pedestrians, cyclists and motorcyclists make up almost half of those killed on the roads, highlighting the need for these road users to be given more attention in road safety programmes. In many countries road safety laws need to be made more comprehensive, while enforcement should be strengthened. The findings of this report clearly show that significantly more action is needed to make the world's roads safer.

Further information and a link to the full report can be found at: http:// www.who.int/violence injury_prevention/road safety status/2009/en/ index.html 